\title{
Reliability Improvement in backup protection schemes using wide area measurement systems
}

\author{
Dr. S. Prakash ${ }^{1}$, Dr.S.Jayaprakash ${ }^{2}$, Dr.A. Suresh ${ }^{3}$ \\ \{prakashacademics@gmail.com ${ }^{1}$,jayaprakash.eee@sathyabama.ac.in², asuresz@gmail.com ${ }^{3}$ \} \\ Bharath Institute of Higher Education and Research, Chennai, Tamil Nadu, India ${ }^{1}$, Sathyabama \\ Institute of Science and Technology, Chennai, Tamil Nadu, India ${ }^{2}$, AMET Deemed to be University, \\ Chennai, Tamil Nadu, India ${ }^{3}$
}

\begin{abstract}
The proposed project envisages a new adaptive scheme of protection that provides a centralized monitoring mechanism using PMU inputs, to achieve the following objectives for a real-time power system : i) to provide assertive trip signal for genuine faults detected in the protected line. i) to provide a blocking signal for spurious faults / load encroachments in the zones of protection. ii) in the absence of PMU data (due to communication failure / equipment failure), the protection schemes will continue to be in service using local measurements. This will enable to overcome certain drawbacks of the traditional protection system which work with local measurements, thereby helping in considerable improvement of security and reliability of monitoring and protection of the electric system. The essential target of any back-up insurance is to give a second line of assurance to clear any blame on the framework. To achieve this goal, the back-up defensive framework must have the option to fulfill the meet the accompanying useful necessities: (1) It ought to catch the life of all issues which emerge inside its endorsed district of wellbeing. (2) It must find the disappointment of the essential wellbeing to clean any blame as intentional. In clearing the flaw from the machine, it need to play out the ensuing highlights : a) start the stumbling of the base assortment of circuit breakers. B) Operate sufficiently fast (reliable with coordination necessities) to safeguard System security, in this manner forestalling unbalanced contraption harm, and protect a recommended level of transporter congruity.
\end{abstract}

Keywords: Phasor measurement unit, Backup protection, zone 3 relay, Wide protection area, control and measurement systems, Wide Area monitoring Systems(WAMS).

\section{Introduction}

Continuous development of modern power system leads to complex interconnected systems. This has prompted the advancement of Wide region interconnection which may thus cause significant power outages those outcomes in genuine consequences for the framework. Over the most recent couple of many years the danger of blackouts has been a genuine worry because of low security and absence of transmission improvement. To beat all these, New advances like sharp matrices has added new norm for insurance, control and following machine to build the security of intensity frameworks, reduce the bothersome power outages, quick response to the extraordinary changes in the electric machine, offer unwavering quality to electric strength, recognition of shortcoming and contraption recuperation as right on time 
as practical. In any case, once in a while extremely minor aggravations can be increment via the chain of exercises fundamental to gadget immense results.

So here, wide area wellbeing and oversee checking contraption is vital for energy control framework. Different deficiencies happen at the transmission line in light of which the device may crumble. There are particular situation like burden infringement, straightforward flaws, islanding and power swings due to this device get influenced comprehensively.

The Wide Area Measuremen introduces a mechanism for adaptive protection putting, backup safety and to come across screw ups etc. A WAMS includes improve statistics tools, dimension technology and it is installation by way of set up of PMUs. The control and expertise of the enlargement of the complex strength system are strengthened using WAMS.During the event of a straightforward flaw at the gadget it is expressed to be the underlying degree of shortcoming and the design of the machine depends on N-1 requirement and works with first deficiency persistently. On the off chance that all the while two events emerge, the gadget is changed to N-2. The auxiliary deficiency as a result of human blunder, guarded transfers or inaccurate examination. Burden infringement is considered as second deficiency circumstance in the machine. Shortcoming happens when burden increments out of nowhere and can cause extreme blackouts. A vivacious blackout power because of overburden is moved to different lines. Force swing is alluded as third shortcoming condition. Because of Power swing in strength contraption, third territory glitch of distance transfer happens in distance wellbeing. Islanding mode is alluded as fourth deficiency condition. Framework voltage self-destruct and strength contraption experience the blackout During the event of a basic shortcoming at the gadget it is expressed to be the underlying degree of deficiency and the format of the machine depends on $\mathrm{N}-1$ imperative and works with first issue ceaselessly. On the off chance that at the same time two events emerge, the gadget is changed to N-2. The auxiliary shortcoming in view of human mistake, protective transfers or wrong investigation. Burden infringement is considered as second issue circumstance in the machine. Flaw happens when burden increments abruptly and can cause extraordinary blackouts. An exuberant blackout power because of over-burden is moved to different lines. Force swing is alluded as third shortcoming condition. Because of Power swing in strength device, third territory glitch of distance hand-off happens in distance security. Islanding mode is alluded as fourth shortcoming condition. Framework voltage self-destruct and strength contraption experience the blackout condition during the islanding method of activity Generally, transmission energy grids are complicated and transmission traces paintings inside the limits. Backup safety structures do no longer rely on Wide Area Measurements as it uses best local dimension. This necessitates backup safety scheme to enhance the safety and reliability.

Phasor Measurement Unit (PMU) is estimating instrument. Utilizing Global Positioning System (GPS), it prepares the synchronized estimations of voltage phasors and current phasors with time tagged. Consideration of the framework conditions, a way for power framework insurance particularly for reinforcement security has been found. On contrasting the magnitude of flows when issue with synchronized current phasor estimations the separation point and area are recognized. A plan utilizing positive grouping synchrophasor information for flaw discovery by contrasting the differential flows determined through PDC has been proposed.

The paper is organised as follows: In Section II Distance protection Relay in malfunction of third zone is discussed. Section III shows wide area Monitoring systems (WAMS). Then in Section IV, The Proposed Supervised Zone-3 Distance Protection SectionV, Differential 
Protection Logic,Section VI. Actual Cases of Spurious operation in Zone-3, Section VII. Simulation using Matlab and VIII. Result and Discussion

\section{Distance Protection Relayand It's Demerits}

Distance hand-off goes about as fundamental assurance for issues inside area 1 while for zone 2 and locale 3, it goes about as reinforcement security for abutting line. Zone 1 accomplish is ordinarily set best as much as eighty $\%-90 \%$ of the covered line. It isn't set one hundred $\%$ of the covered line to evade hand-off from underneath came to or over came to because of current and voltage estimation botches, brief effect and incorrectness in transmission line boundaries. On the off chance that a shortcoming happened inside this region in which distance hand-off goes about as fundamental security, the hand-off will without a moment's delay transport ride sign to open the electrical switch. The resulting $10 \%$ assurance edge guarantees that need to cowl the excess $10 \%$ of the street. The territory 2 covers the leftover part of the line in addition to 20 reliable with penny of the following briefest line and activity time is going to about there is no danger of the Zone - 1 security over-achieving the included line as a result of mistakes in the present day and voltage transformers, errors in line impedance data accommodated setting capacities and blunders of transfer putting and estimation of the space assurance zero.2 to 0 .Three seconds. The stumbling time for zone 2 ordinarily set at various hundred milliseconds. Reinforcement assurance for complete nearby line is incorporated through district 3 reach. It is commonly set in any event 1.2 cases the impedance of ensured abutting line. The set stumbling time for zone three reach is commonly various seconds.

Third zone covers the whole region ensured by the first and second zones in addition to 50 percent of the following long queue (third line) and postpone time is set between 0.5 to 1.0 seconds..

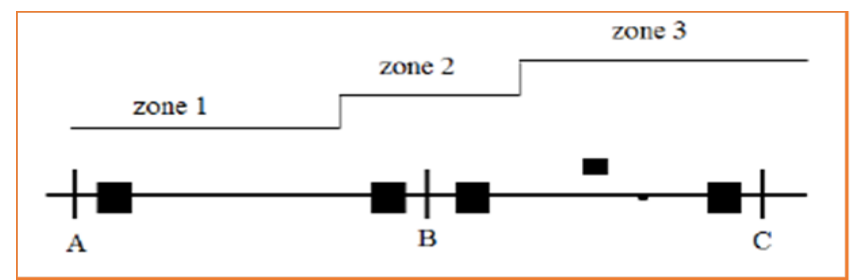

Fig 1. layout of three zones of Distance Relay operation

The relay whose working relies upon on the space between the impedance of the faulty segment and the position on which relay set up is known as the impedance relay or distance relay. It is a voltage controlled gadget. For lower fault resistance, the impedance is proportional to the space from the relay to the fault. A distance relay is designed to most effective function for faults happening between the relay location and the chosen reach point and stays solid (or inoperative) for all faults out of doors this vicinity or region. Each relay operates independently according to the 3 distinctive kind quarter of protection as shown in Fig.1 


\section{Wide Area Monitoring System (WAMS)}

Wide region checking frameworks (WAMS) depend on the fresh out of the box new data procurement innovation of phasor estimate and permit the following transmission contraption circumstances over immense areas considering recognizing and moreover balancing lattice hazards. The WAMS framework obliges of the Phasor estimation unit (PMU) and Phasor insights concentrator (PDC). Current, voltage and recurrence estimations are taken via Phasor Measurement Units (PMUs) at settled on areas in the force machine and put away in a realities concentrator (PDC) every 100 milliseconds. The deliberate bits incorporate the two sizes and section points, and are time-synchronized through Global Positioning System (GPS) collectors with an exactness of 1 microsecond. A Phasor insights concentrator gets two or three PMU data streams, plays circulate statistics fee conversion in which required, time aligns the steam and repacks the streams into one or more output streams for transmission to other systems require phasor data.

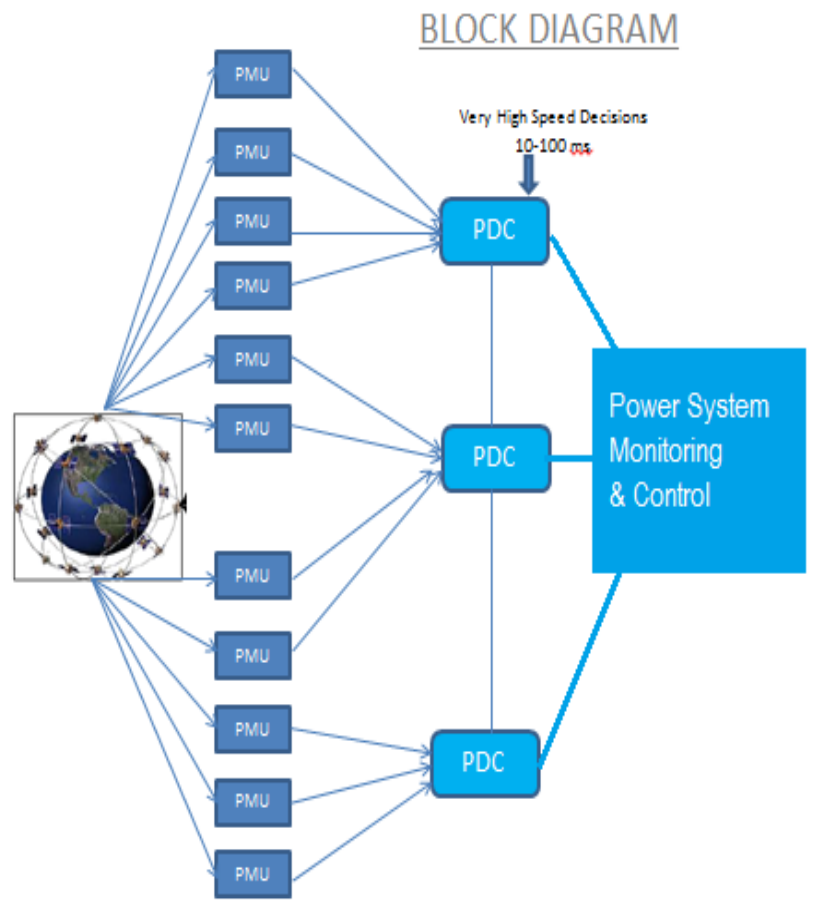

Fig2. Wide Area backup protection system

This system operates as backup protection system for WAMS and it is substation of conventional backup protection in power system. 


\section{The Proposed Supervised Zone-3 Distance Protection}

The PMUs to measure 25 samples per sec makes them suitable for analysing the system under dynamic conditions. The PMUs transmit line current and bus/line voltage synchro phasor to PDC Centralised location. The PDC creates time snapshot for the system.

To avoid time delays in PMU for protection applications, it is preferable to use P-type PMUs as they are fast. Connect PMUs to protection core of CTs. They will not saturate on fault current. The supervisory analytic is centralized and located at the location of the PDC.

With PMUs placed at both ends of the transmission lines, differential currents can be computed. Once differential currents for all backed up lines are available, decision to block or not block Zone-3 of the backup relay can be taken. The whole procedure of obtaining synchrophasor from PMUs differential current computation communicating appropriate decision to relay should happen well within one second.

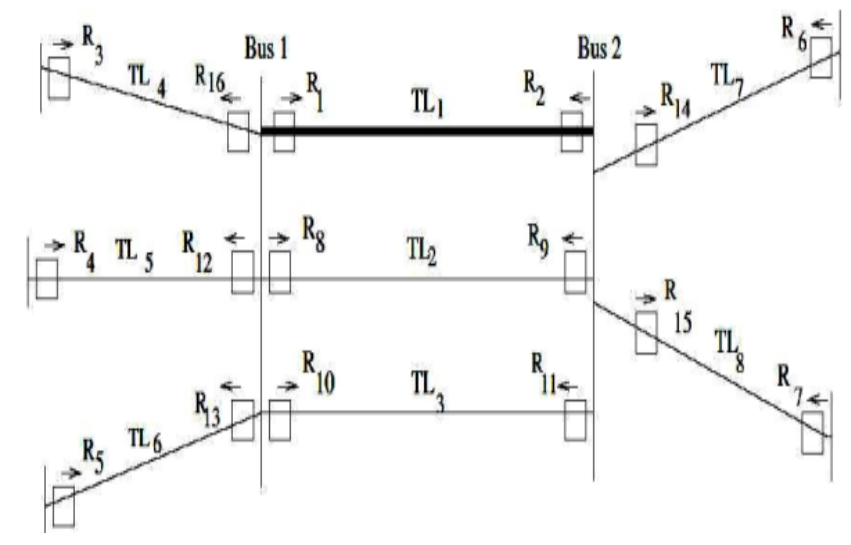

Primary relays for line TL1 $=\mathrm{R} 1 \& \mathrm{R} 2$

Zone-3 back-up relays associated with $\mathrm{R} 1: \mathrm{B} 1=\{\mathrm{R} 3 ; \mathrm{R} 4 ; \mathrm{R} 5 ; \mathrm{R} 9 ; \mathrm{R} 11\}$

Zone 3 back relays associated with $\mathrm{R} 2: \mathrm{B} 2=\{\mathrm{R} 6 ; \mathrm{R} 7 ; \mathrm{R} 8 ; \mathrm{R} 10\}$

Zone-3 of R3 backs up following set of relays: $\mathrm{P} 3=\{\mathrm{R} 1 ; \mathrm{R} 8 ; \mathrm{R} 10 ; \mathrm{R} 12 ; \mathrm{R} 13\}$.

i.e., during fault (which is not yet cleared by primary

Protection) on any one of the lines TL1, TL2, TL3, TL5, TL6,

Then Z3 of R3 must operate.

\section{Differential Protection Logic}

A fault which has not been cleared by primary protection s systems can be detected by differential protection logic. This can be implemented by using positive(1), negative(2) and zero sequence(0)synchrophasor line currents. Since the Zone-3 time delay setting is of the order of a second, and PMU reporting time 40 milliseconds, the fault can be detected in multiple and successive PMU frames. 


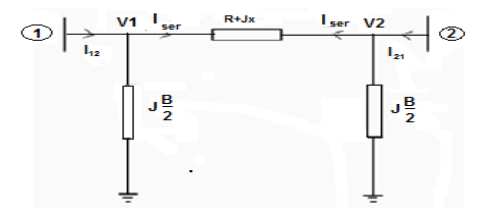

Fig 4. Differential protection Scheme for a Line

- $\psi$ functions are defined as:

$$
\begin{aligned}
& \psi\left(V_{1}, V_{2}\right)=j \frac{B}{2}\left(V_{1}+V_{2}\right) \\
& \underline{\psi}\left(V_{1}, V_{2}\right)=j \frac{B}{2}\left(V_{2}-V_{1}\right)
\end{aligned}
$$

- Fault detection logic using differential currents can be given to be:

- Zero sequence differential current

$$
I_{\text {diff }}^{0}(k)=\left|\frac{{\overrightarrow{I_{2}}}^{0}(k)+{\overrightarrow{I_{21}}}^{0}(k)-\psi^{0}\left(V_{1}^{0}, V_{2}^{0}\right)}{\overrightarrow{I_{12}} 0(k)-{\overrightarrow{I_{21}}}^{0}(k)+\underline{\psi}^{0}\left(V_{1}^{0}, V_{2}^{0}\right)}\right| \times 100 \%
$$

- Positive sequence differential current

$$
I_{\text {diff }}^{1}(k)=\left|\frac{\overrightarrow{I_{12}} 1(k)+{\overrightarrow{I_{21}}}^{1}(k)-\psi^{1}\left(V_{1}^{1}, V_{2}^{1}\right)}{\overrightarrow{I_{12}} 1(k)-{\overrightarrow{I_{21}}}^{1}(k)+\underline{\psi}^{1}\left(V_{1}^{1}, V_{2}^{1}\right)}\right| \times 100 \%
$$

- Negative sequence differential current

$$
I_{\text {diff }}^{2}(k)=\left|\frac{{\overrightarrow{I_{12}}}^{2}(k)+{\overrightarrow{I_{21}}}^{2}(k)-\psi^{2}\left(V_{1}^{2}, V_{2}^{2}\right)}{\overrightarrow{I_{12}}(k)-{\overrightarrow{I_{21}}}^{2}(k)+\underline{\psi}^{2}\left(V_{1}^{2}, V_{2}^{2}\right)}\right| \times 100 \%
$$

- If $I_{\text {diff }}(k)^{012} \leq \varepsilon^{012}$ then no fault exists on the line $\mathrm{k}$.

- The value of $\varepsilon^{0}, \varepsilon^{1}, \varepsilon^{2}$ can be between 1 - $10 \%$

The approach monitor the fault on the designated line

e.g., TL1.

Primary design attribute: Line

Secondary design attribute: Set of backup relays for the line. If differential logic indicates fault on the line, then PDC raise TRIP FLAG for set of back up relays (B1 and B2).

ASSERT TRIP decision for a relay is obtained by OR operation on ASSERT TRIP flags for the lines it is backing up (FOR R3 -> P3). If differential protection logic indicates a healthy line (e.g., TL1), raise BLOCK FLAG for the backup relays (B1 U B2).

For a given backup relay, (R3), perform AND operation on the BLOCK FLAGS of corresponding set of primary lines. (P3). If resulting decision is amative, ASSERT BLOCK is 
issued for relay R3. If PMU data is unavailable and ASSERT TRIP is not obtained on any of the primary lines, system defaults to ENABLE TRIP (B1 and B2).

\section{ACTUAL CASES OF SPOURIUS OPERATION IN ZONE3:}

The Actual tripping events happened Southern region of our country for spurious fault of Zone -3 protection from Southern Region Protection Committee (SRPC), Government of India web site.

Table 1.Zone -3 Trip Cases

\begin{tabular}{|l|l|l|}
\hline & Date \& Time & Line Details \\
\hline 1 & $\begin{array}{l}17-05-2019 \text { at } \\
14: 10 \mathrm{Hrs} .\end{array}$ & $\begin{array}{l}\text { APTRANSCO 400kV Kurnool- } \\
\text { Srisailam line }\end{array}$ \\
\hline 2 & $\begin{array}{l}18.05 .19 \\
12.13 \mathrm{Hrs} .\end{array}$ & 220KV Ambewadi-Ponda line \\
\hline 3 & $\begin{array}{l}14.06 .19 \\
14.00 \mathrm{Hrs} .\end{array}$ & $\begin{array}{l}\text { 220KV Sedam - RTPS line-1\&2 } \\
\text { (Generation loss) }\end{array}$ \\
\hline 4 & $\begin{array}{l}07.02 .19 \\
11.49 \mathrm{Hrs}\end{array}$ & $\begin{array}{l}\text { KPTCL }-400 \mathrm{KV} \mathrm{Lingapuram-} \\
\text { Guttur Line Tripped at ZONE-3 }\end{array}$ \\
\hline 5 & $\begin{array}{l}27.03 .19 \\
17.45 \mathrm{Hrs} .\end{array}$ & $\begin{array}{l}\text { KPTCL }- \text { 220KV BTPS to } \\
\text { Lingapuram Line Tripped at } \\
\text { ZONE-3 }\end{array}$ \\
\hline 6 & $\begin{array}{l}08.04 .19 \\
16.11 \mathrm{Hrs} .\end{array}$ & $\begin{array}{l}\text { APTRANSCO - 400KV Srisailum- } \\
\text { Nanoor Tripped } \\
\text { Indication of Zone-3 }\end{array}$ \\
\hline
\end{tabular}

\section{Simulation Using Matlab}

The accompanying 5 transport network is taken for the contextual analysis. MATLAB/Simulink pack is utilized to mimic the organization and the proposed set of rules is done and researched. The PMU position is in like manner completed, $220 \mathrm{KV}$ interconnected transmission line network, a hundred $\mathrm{km}$ transmission line. Producing station on one angle and on the other aspect is load each are connected through interconnected follows. Diverse flaw circumstances are reproduced on that line the utilization of MATLAB programming program. The qualities indicated are in as per unit on a hundred MVA (base).

The transmission line positive and zero succession Parameters are $\mathrm{R} 1=0.10809 \Omega / \mathrm{km}$, $\mathrm{R} 0=0.2188 \Omega / \mathrm{km}, \mathrm{L} 1=0.00092 \mathrm{H} / \mathrm{km}, \mathrm{L} 0=0.0032 \mathrm{H} / \mathrm{km}, \mathrm{C} 1=1.25^{*} 10-8 \mathrm{f} / \mathrm{km}, \mathrm{C} 0=7.85^{*} 10-9 \mathrm{f} / \mathrm{km}$. The allotted parameter model of transmission line is taken into consideration for evaluation. A sampling frequency of $20 \mathrm{KHz}$ for a system working at a frequency of $50 \mathrm{~Hz}$ is used on this examine. To reveal the capability of the technique most effective few cases of fault occurrence are proven here. $\mathrm{KHz}$ for a system operating at a frequency of fifty $\mathrm{Hz}$ is used on this examine. To show the ability of the approach most effective. 
Simulation version

The Three phase to ground fault are placed on

Transmission line (TL2) connecting vicinity"1" and place "three" as shown in fig.5. The output three section voltage waveforms, modern-day wave forms and TRIP \& BLOCK

Signal are shown below in fig. $6 \& 7$ respectively.

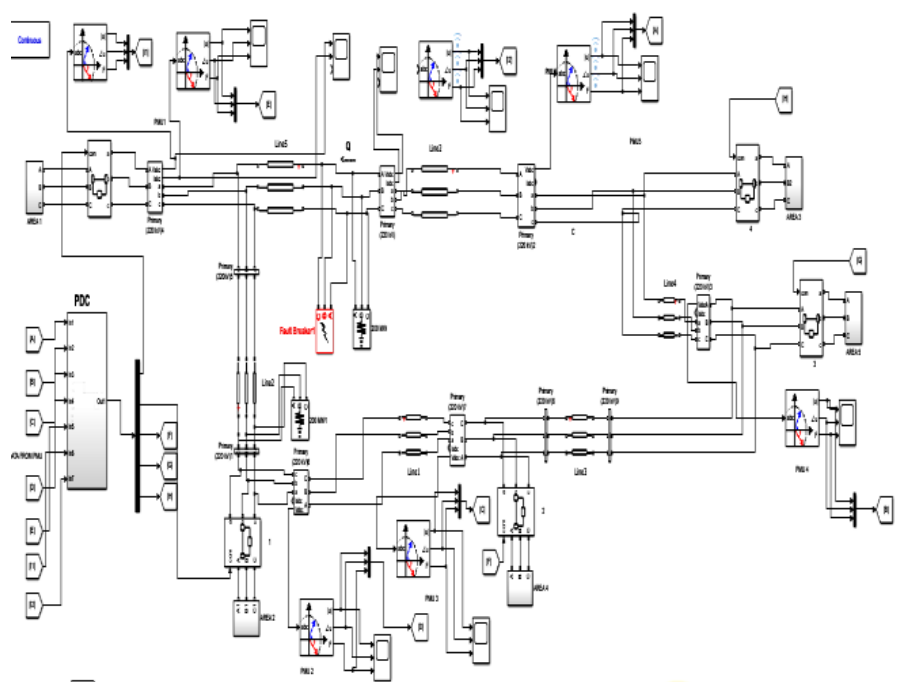

Fig 5. Simulation model

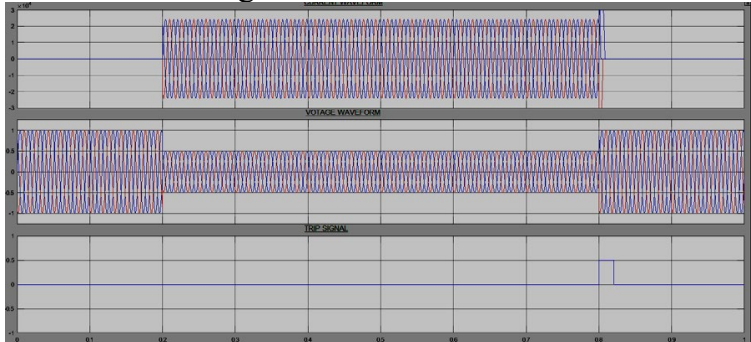

Fig 6. Voltage, Current \& Trip Signal

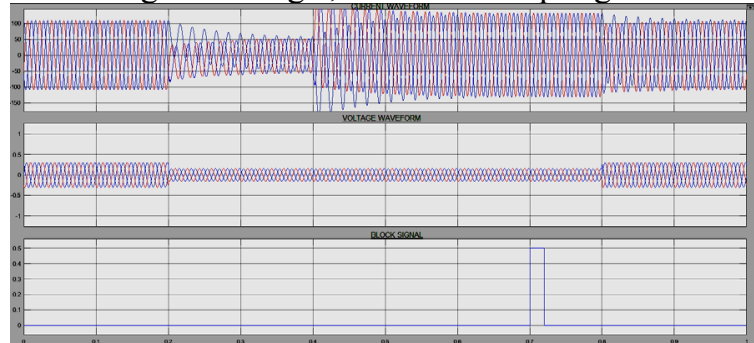

Fig 7. Voltage, Current \& Block Signal 


\section{Result \& Discusstion}

In segment 5 we seen three distinctive Zone-3 shortcoming stumbling misleading instances of various area in southern force district of India year 2019. The proposed calculation structure is reasonable for evading such conditions and give powerful reinforcement insurance (zone-3 ) and furthermore distinguished the blamed line everywhere on the transmission interface framework. In contrast to the current procedures, it gives improvement of dependable security to the force framework and evade immense business misfortunes because of Blackouts, Generation misfortune.

\section{Conclusion}

A Wide Area Backup Protection plot for transmission follows in wide district framework utilizing PMUs is proposed in the paper. It utilizes time labeled realities of Wide Area Measurement System. Based at the high-caliber and zero succession flows entering the Backup Protection Zone is molded. Conventional back-up insurance plans are one-sided towards steadfastness. Be that as it may, the proposed plan can change its security/constancy predisposition to solid winning strength device situations. By doing this, the likelihood of fell blackouts due to hand-off mal-tasks can be kept away from. Since zone-3 is a relatively moderate security plot with working season of the request for a second, phasor data (PMU based) of a WAMS can be utilized to manage the zone-3 transfer. Consequently, the presentation of the zone-3 security plan can be improved.

\section{References}

[1] Shalini, Subhransu Ranjan Samantaray, Ankush Sharma "Transmission Line Back- up Protection with Unreliable PMU Data “ IEEE Proceedings of the National PowerSystems Conference (NPSC) - 2018, December 14-16, NIT Tiruchirappalli, India

[2] A.P.Vaidya, Prasad A. Venikar," Distance Protection of Long Transmission Lines by Considering the Effect of Fault Resistance," IEEE - International Conference On Advances In Engineering, Science And Management (ICAESM -2012) March 30, 31, 2012.

[3] Manas Kumar Jena, S.R.Samantaray , B.K Panigrahi "A New Wide Area Back-up Protection scheme for series - compensated Transmission system" IEEE- Systems Journal ,vol PP no.99 pp,111.

[4] G.Kavya, M.MeenakkshiDevi, Dr. M.Geethanjali "Wide Area Backup Protection Scheme using Optimal PMUs" IEEE- 2018 National Power Engineering Conference (NPEC) .

[5] M. M. Eissa, Senior, M. Elshahat Masoud, and M. Magdy Mohamed Elanwar, "A Novel Back up Wide Area Protection Technique for Power Transmission Grids Phasor Measurement Unit," IEEETRANSACTIONS ON POWER DELIVERY, VOL. 25, NO. 1, JANUARY 2010.

[6] S.Karthick , K.Lakshmi "Wide Area Backup Protection Scheme for Power Transmission Lines using PMU” by International Research Journal of Engineering and Technology [IRJET] Vol- 02, Issue:09 Dec-2015.

[7] Shital Uttam Karpe, M N Kalgunde,"power system backup protection in smart grid using synchronised PMU”, IEEE conf, Jun. 2017.

[8] S Lakshmi, R Ramaprabha. "A Novel Multiphase Interleaved Quadrupler Circuit With Reduced Voltage Stress And Ripples For Photovoltaic Applications". Int Trans Electr Energ Syst. 2020; e12317. https://doi.org/10. 1002/2050-7038.12317 
[9] S Lakshmi, R Ramaprabha., "Stability Evaluation Of Four Phase High Gain Converter By Small Signal Modeling” Rev. Roum. Sci. Techn.- Électrotechn. et Énerg. Vol. 65, 1-2, pp. 75-80, October 2020.

[10] Lakshmi S, "Closed-Loop Control of a DC-DC Four-Phase Interleaved Quadrupler for Solar Photovoltaic Applications" IEEE International WIE Conference on Electrical and Computer Engineering (WIECON-ECE), November 2019.

[11] S. Lakshmi , R. Ramaprabha, "Design And Analysis Of An Improved High Gain Non Isolated Interleaved Boost Converter For Solar Photovoltaic Applications" Journal of Electrical Engineering, Politehnica publishing house. Volume 18 / 2018 - Edition: 4, pp: 1210- 131 